\title{
A systematic analysis of intrinsic regulators for HIV-1 R5 to X4 phenotypic switch
}

\author{
Wei $\mathrm{Yu}^{1}$ and $\mathrm{Yu} \mathrm{Wu}^{1,2,3, *}$ \\ 1 Department of Engineering Mechanics, Zhejiang University, Hangzhou 310027, China \\ 2 Key Laboratory of Soft Machines and Smart Devices of Zhejiang Province, Zhejiang University, Hangzhou 310027, China \\ ${ }^{3}$ Soft Matter Research Center, Zhejiang University, Hangzhou 310027, China \\ * Correspondence: ywu@zju.edu.cn
}

Received January 19, 2017; Revised March 20, 2017; Accepted March 30, 2017

\begin{abstract}
Background: Human immunodeficiency virus isolates most often use chemokine receptor CCR5 or CXCR4 as a coreceptor to enter target cells. During early stages of HIV-1 infection, CCR5-tropic viruses are the predominant species. The CXCR4-tropic viruses may emerge late in infection. Recognition of factors influencing this phenotypic switch may give some hints on the antiviral strategies like anti-HIV/AIDS drugs, gene therapy and vaccines.

Methods: To investigate the mechanism that triggers $\mathrm{R5}$ to $\mathrm{X} 4$ phenotypic switch, we performed a systematic sensitivity analysis based on a five-dimensional model with time-varying parameters. We studied the sensitivity of each factor to the CCR5-to-CXCR4 tropism switch and acquired some interesting outcomes beyond expectation.

Results: The death rate of free virus $\left(d_{V}\right)$, rate that uninfected $\mathrm{CD}^{+} \mathrm{T}$ cells arise from precursors $(s)$ and proliferate as stimulated by antigens $(r)$, and in vivo viral burst size $(N)$ are four robust factors which are constantly observed to have a strong correlation with the evolution of viral phenotype for most patients longitudinally.

Conclusions: Crucial factors, which are essential to phenotypic switch and disease progression, are almost the same for different patients at different time points, including the production of both virus and $\mathrm{CD4}^{+} \mathrm{T}$ cells and the decay of virion. It is also worth mentioning that although the sequence of factors sorted by the influence varies between patients, the trends of influences engendered by most factors as disease progresses are similar inter-patients.
\end{abstract}

Keywords: HIV-1; R5-to-X4 switch; two-strain model; population dynamics; sensitivity analysis

\section{INTRODUCTION}

Human immunodeficiency virus type 1 (HIV-1) entry into target cells (T helper cells, macrophages, etc.) is mediated not only through interaction of the virion envelope glycoprotein (gp120) with the CD4 molecule on the surface of cells, but also with its chemokine co-receptors. Several chemokine receptors can function as viral coreceptors, but the beta-chemokine receptor CCR5 and alpha-chemokine receptor CXCR4 are the most physiologically important co-receptors during natural infection. CCR5-tropic (R5) HIV-1 isolates use CCR5 on target cells for a productive infection, while CXCR4-tropic (X4) isolates use CXCR4. Early HIV infection is characterized by the predominance of R5 virus. However, later in the course (usually after 8 to 10 years [1]), X4 virus emerge in about $50 \%$ patients [2]. The mechanisms for this phenotypic switch are still unknown [3]. It is also unclear whether the evolution of $\mathrm{X} 4$ virus can result in a faster disease progression $[4,5]$, but this phenomenon has been surely associated with a rapid decrease in $\mathrm{CD}^{+}{ }^{+} \mathrm{T}$ cells and led the disease to the AIDS phase [6]. Figuring out the drivers of R5-to-X4 phenotypic switch is crucial for the development of antiretroviral therapy.

Many hypothesizes have been raised to address this question. It has been suggested that the availability of target cells may not be a driver for the R5-to-X4 switch [7]. As observed by Van Rij RP, after one year of infection, the occupation of serum CXCR $4^{+} \mathrm{CD} 4^{+} \mathrm{T}$ cells was inversely correlated with the evolution of $\mathrm{X} 4$ viruses and the occupation of $\mathrm{CCR} 5^{+} \mathrm{CD} 4^{+} \mathrm{T}$ cells has no relationship with the phenotypic switch [8]. Another assumption is that $\mathrm{X} 4$ virus might have higher infectivity than R5 virus. However, this explanation cannot explain 
why X4 virus does not appear from the early stage of infection, since it only required a few amino acid changes in V3 loop for virus to switch from CCR5 to CXCR4 tropism [9-13]. In contrary, in early stage, most switch showed reduced replication rate and less-efficient coreceptor use [1]. It has also been suggested that selective pressure restrains the evolution of $\mathrm{X} 4$ viruses in vivo, which indicates that the appearance of CXCR4-tropic isolates late in the infection reflecting the languishing immune system [7]. R5 viruses were thought to have a selective superiority in vivo and the burst size of R5 viruses has been suggested to be much greater than that of $\mathrm{X} 4$ viruses [14]. Additionally, a recent study has shown that the turnover of memory and naïve $T$ cells can also result in this phenomenon [3]. Memory T cells in division have relatively high proportion in the early phase of infection and thus benefits the division of memory celltropic (R5) viruses. With the increase of the proportion of active naïve T cells, the amount of X4 viruses exceeds that of R5 counterpart [3]. However, most of the presumptions just focused on one aspect and did not explain how these factors jointly influence the evolution of X4 virus.

In this paper, we present a time-dependent model incorporating mutation rate to describe the dynamic progression of HIV-1 from R5-dominance to X4dominance. Based on some assumptions mentioned above, we expect to assess the significance of every essential element in the evolution of viral phenotype switch comprehensively. Therefore we conducted a new systematic evaluation by performing sensitivity analyses from different time sections both inter- and intra-patients. The results suggest that, besides mutation rate, whether coreceptor switch emerges or not depends mostly on the factors relevant to the renewal of $\mathrm{CD}^{+} \mathrm{T}$ cells and viruses. We demonstrate that the death rate of free virus $\left(d_{\mathrm{V}}\right)$, rate that uninfected $\mathrm{CD}^{+} \mathrm{T}$ cells arise from precursors $(s)$ and proliferate as stimulated by antigens $(r)$, and in vivo viral burst size, i.e., the number of free virions released from an infected $\mathrm{CD} 4^{+} \mathrm{T}$ cells during its lifespan $(N)$ are four robust factors which are constantly observed to have a strong correlation with the evolution of viral phenotype for most patients longitudinally, although the most sensitive factor changes with the alternation of physical conditions.

\section{RESULTS}

Infection was established using System 2 in Methods by 1 viral particle $/ \mathrm{mL}$ of $\mathrm{R} 5$ virus and the results correlate well with the features mentioned by other experimental observations (Figure 1 and Figure 2A). In the acute infection, $\mathrm{CD}^{+}{ }^{+} \mathrm{T}$ cell numbers declined, followed by a slight recovery and then fluctuated for about one year. Meanwhile, the number of R5 virus ascended and experienced a fluctuation as well. As the amount of $\mathrm{CD}^{+}{ }^{+} \mathrm{T}$ cells declined, the virus accumulated mutations [15], and thus the evolution towards CXCR4 usage appeared at a low CD4 counts, which correlates well with the observed features that the emergence of $\mathrm{X} 4$ virus is usually related to the decrease in CD4 counts [16] Notably, R5 virus did not disappear after the switch [17] Actually, whether the switch would happen and the percentage of R5 virus in total virus load depends on the model parameters. This phenomenon is consistent with

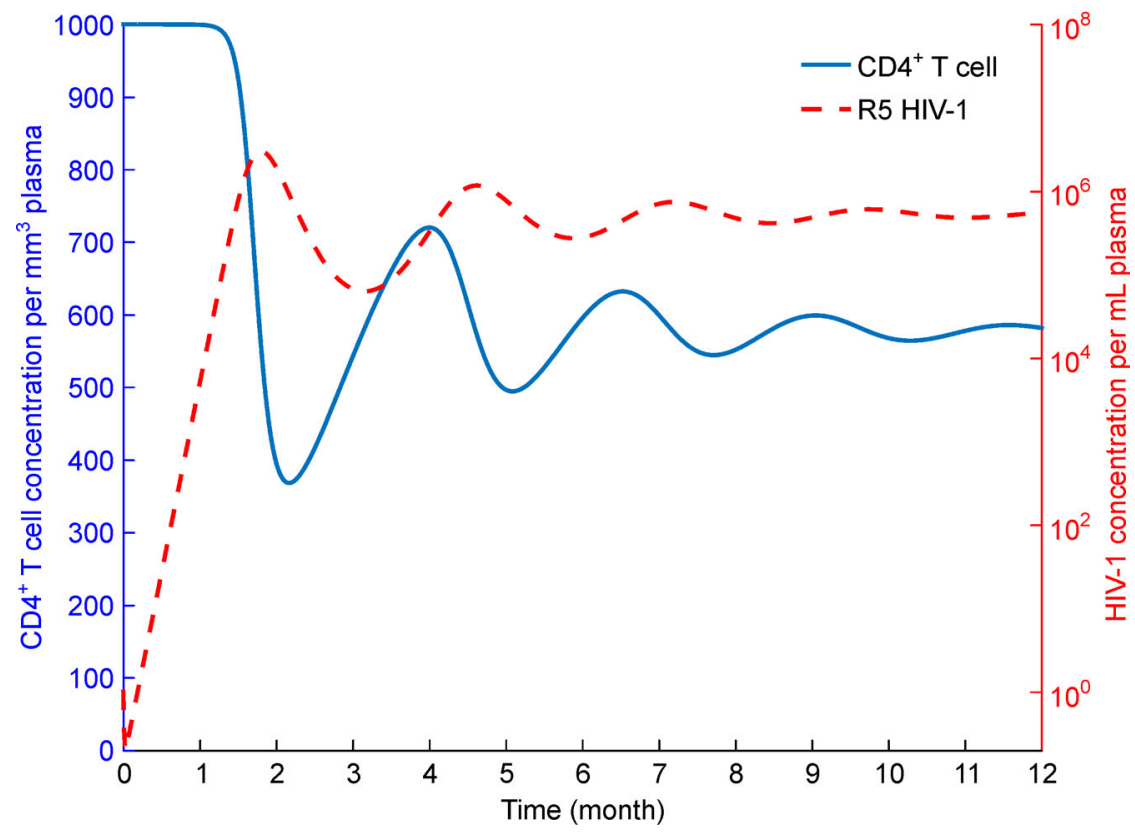

Figure 1. Evolution of the concentrations of $C D 4^{+} \mathrm{T}$ cells and R5 HIV-1 in the first year. 

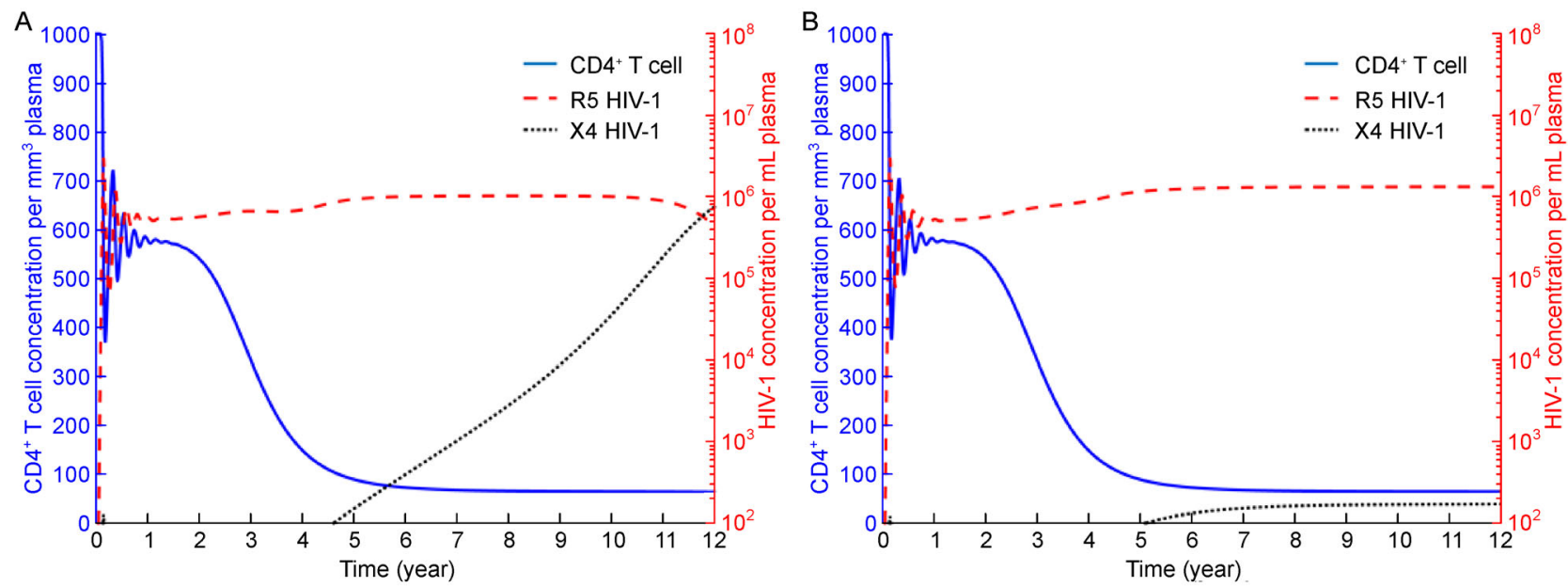

Figure 2. Evolution of the concentrations of $\mathrm{CD}^{+} \mathrm{T}$ cells, R5 HIV-1 and X4 HIV-1 with different initial values. (A) Model with parameters shown in Supplementary Table S1. (B) Model with infectivity of X4 virus $k_{X 4}=3 \times 10^{-5} \mathrm{~mm}^{3} \mathrm{day}^{-1}$. All the other parameters were adopted from Supplementary Table S1.

the records that X4 virus can be examined in only $50 \%$ patients even in the late stage [18] and different patients experience the switch at various time points. Although it is still unknown whether the emergence of X4 tropism is the cause or the result of rapid CD4 ${ }^{+} \mathrm{T}$-cell decline, all the patients with $\mathrm{X} 4$ virus experienced a faster progression [18].

\section{Key factors that dominate the likelihood of phenotypic switch}

It is poorly understood why coreceptor switch happened in 50\% of HIV-1 patients. Trouplin et al. found that just few mutations in the V3 loop can result in the utilize of CXCR4 [15]. While few assumptions mentioned the role of mutation in the phenotypic switch, many hypotheses focused on target cell availability, cell turnover, viral infectivity and immune pressure [7]. To explore the possibility of alternative proposals, we let all the parameters fluctuate around their original values at different time points. The influences of perturbation on the likelihood to switch were calculated following the protocol of sensitivity analysis mentioned in the Section of Method. Basically, a positive factor is supposed to promote the switch, and vice versa. According to the results, the exact value of mutation rate played a less important role in the R5-to-X4 switch. That is to say, though this factor was essential for the occurrence of switch, it was not sensitive to the likelihood to switch. This is probably because sensitivity analysis focused mainly on the horizontal comparisons between several parameters at different time points. The parameters with larger base value are more likely to be prominent sensitivity factors. If we enlarged the rate, the sensitivity would raise as well (not shown). For the same reason, the percentages of total and dividing naïve T cells $\left(f_{\mathrm{n}}\right.$ and $n$ ) showed weak effects as well.

How factors affect the likelihood of R5-to-X4 switch in specific was illustrated by patient 1 (Figure 3 ). The results indicated that the death rate of free viruses $\left(d_{\mathrm{V}}\right)$, in vivo viral burst size $(N)$, rate that uninfected $\mathrm{CD}^{+}{ }^{+}$T cells arise from precursors $(s)$ and proliferate as stimulated by antigens $(r)$ had strong impacts on viral phenotypic switch longitudinally. Among these factors, $d_{\mathrm{V}}$ was the most sensitive positive one and $N$ remained the most sensitive negative one through the disease progression. Different from the two factors mentioned above, as HIV-1 progressed, the impact of $s$ increased while the influence of $r$ diminished.

Interestingly, the effect of R5 infectivity $\left(k_{\mathrm{R} 5}\right)$ was negative when the count of $\mathrm{CD} 4^{+} \mathrm{T}$ cells is relative high (over 200). However, it turned into positive on the later stage. This may result from the lack of target cells. In early infections, higher infectivity would contribute to more infected $\mathrm{CD} 4^{+}$T-cells which release $\mathrm{R} 5$ virus. However, in late-stage disease, the amount of $\mathrm{CD} 4^{+} \mathrm{T}$ cells had already declined. At this time, higher infectivity of R5 strains would make this drop more dramatic so that both 2 subspecies would not have enough host cells to invade. Due to a higher basic value of R5 virus, the decrease of R5 virus load was more outstanding than its counterpart and gave rise to the increase of the difference value. Moreover the absolute value of its influence ascended from the latter half of chronic infection.

Comparing with the rest of the factors, the impact of the percentage of dividing memory $\mathrm{CD}^{+}{ }^{+} \mathrm{T}$ cells $(m)$ was 

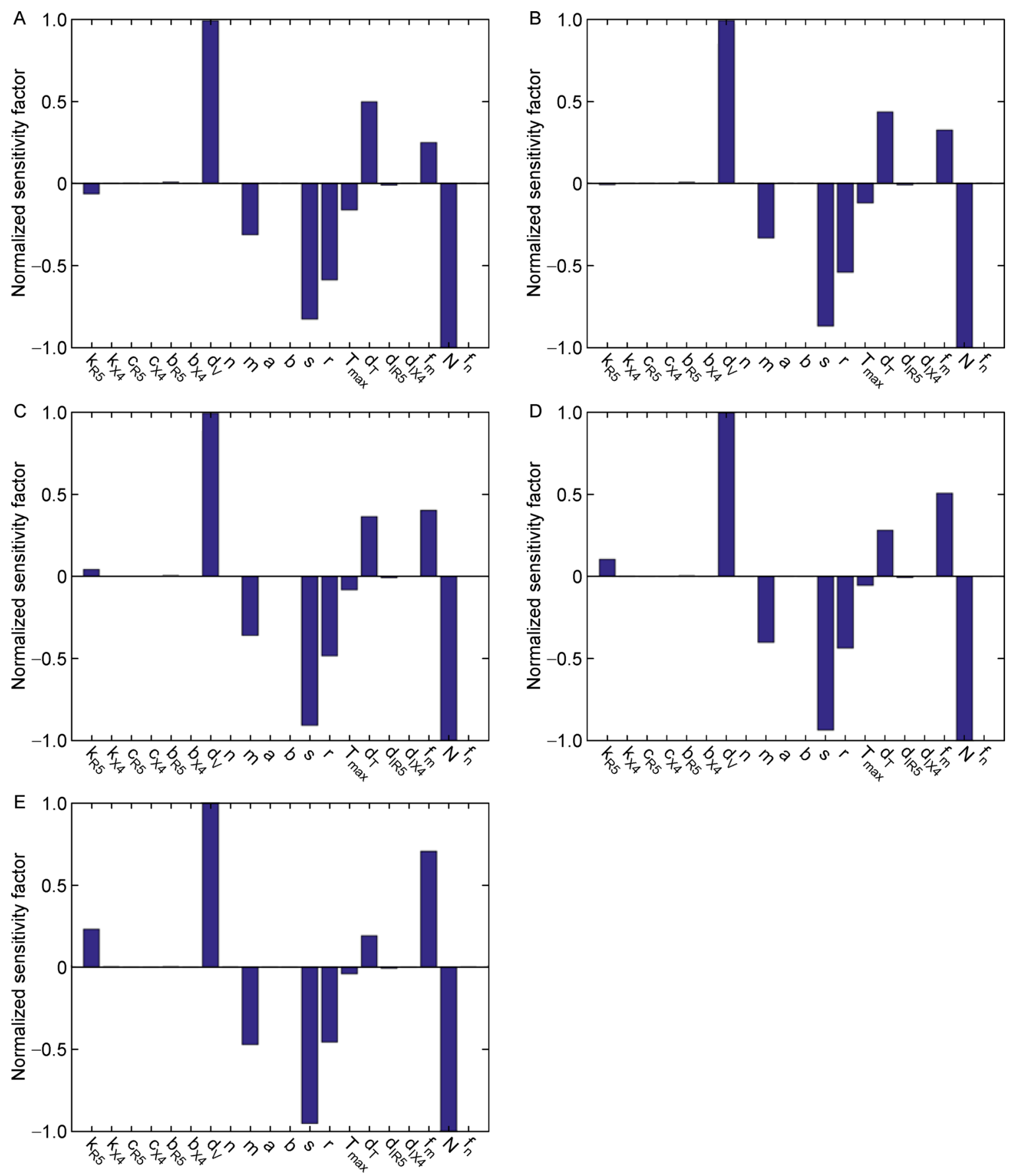

Figure 3. Sensitivity analysis of patient 1 . The perturbation analyses were performed when $C D 4^{+} \mathrm{T}$ cells reach specific concentration (A) $T=300$; (B) $T=250$; (C) $T=200$; (D) $T=150$; (E) $T=100$. Parameter values used are given in Supplementary Table S1.

relatively remarkable and increased as disease went on. It is consistent with the result from Riveiro et al. [3]. The influence of the proportion of total memory $\mathrm{CD} 4^{+} \mathrm{T}$ cells $\left(f_{\mathrm{m}}\right)$ experienced a similar trend. The difference was that $f_{\mathrm{m}}$ showed a positive effect on the likelihood of switch, which was opposite to $m$. As for the maximum $\mathrm{CD}^{+}{ }^{+} \mathrm{T}$ cell concentration level ( $T_{\max }$, negative) and death rate of uninfected $\mathrm{CD} 4^{+} \mathrm{T}$ cells $\left(d_{\mathrm{T}}\right.$, positive), they all exhibited a decreased influence with the depletion of $\mathrm{CD} 4^{+} \mathrm{T}$ cells. All the parameters were designed randomly within the biological significance and details of patients are included in Supplementary Table S1. 


\section{Contribution of inter-patient heterogeneity to the likelihood of switch}

To assess the effects of patient heterogeneity on the phenotypic switch and evolution of disease progression, we performed a sensitivity analysis for seven virtual patients with different physical conditions. In our modeling, only a fraction of these targeted parameters are immeasurable $\left(b_{\mathrm{R} 5}, b_{\mathrm{X} 4}, c_{\mathrm{R} 5}, c_{\mathrm{X} 4}, T_{\max }\right)$, while most of them $\left(b_{\mathrm{R} 5}, b_{\mathrm{X} 4}, c_{\mathrm{R} 5}, c_{\mathrm{X} 4}\right)$ had little impact on the final results. The results show that the parameters with high sensitive score remain steady across all patients (Figure 4). The parameter settings of 7 virtual patients can be found in Supplementary Table S3. To verify our
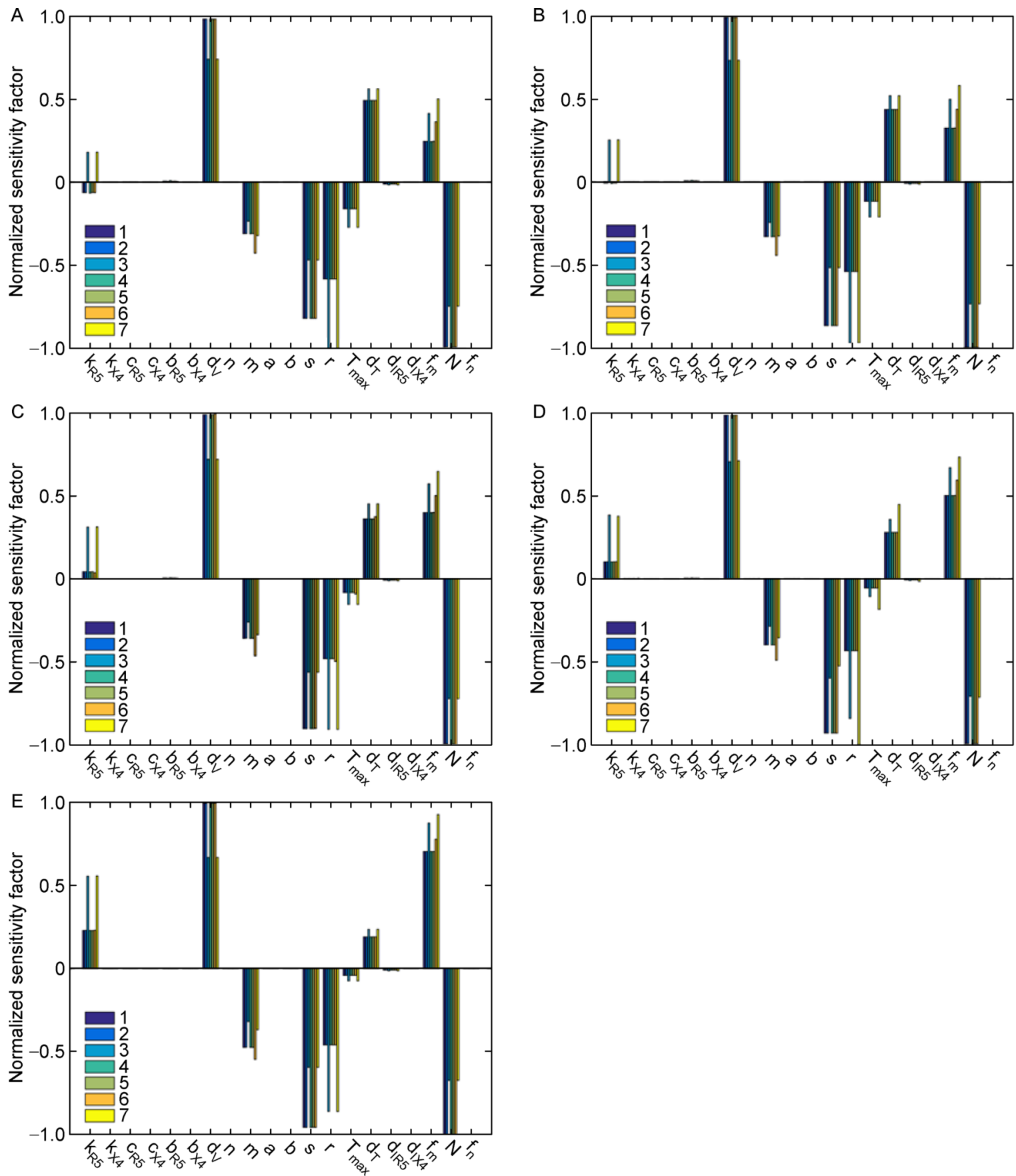

Figure 4. Sensitivity analyses of 7 patients with different profiles. The perturbation analyses were performed when $C D 4^{+} T$ cells reach specific concentration (A) $T=300$; (B) $T=250$; (C) $T=200$; (D) $T=150$; (E) $T=100$. Parameter values used and the 3D version are given in Supplementary Table S3 and Figure $S 1$ respectively. 
conclusions, we have performed sensitive analyses for additional virtual patients with different parameter settings (see Supplementary Materials for detail) and selected seven representative patients for following analyzing. The results indicate that the variations in most parameters of patients' profile had little effect on the sensitivity analyses, expect for these four factors: the rate that uninfected $\mathrm{CD} 4^{+}$T cells arise from precursors $(s)$, the rate that unifected $\mathrm{CD} 4^{+} \mathrm{T}$ cells as stimulated by antigens $(r)$, the percentage of total memory $\mathrm{CD} 4^{+} \mathrm{T}$ cells $\left(f_{\mathrm{m}}\right)$ and the percentage of dividing memory $\mathrm{CD}^{+} \mathrm{T}$ cells $(m)$. Specifically, when the magnitude of $r$ raised and that of $s$ decreased (patient 3), the influence of the infectivity of R5 $\left(k_{\mathrm{R} 5}\right)$ to likelihood was strengthened. Notably, for patient 1 , the sensitivity factor of $k_{\mathrm{R} 5}$ was negative.

However, when $s$ and $r$ changed, the effect turned into positive. Meanwhile, the modification of $s$ and $r$ also contributed to larger influence of $r$ itself, the maximum $\mathrm{CD}^{+} \mathrm{T}$ cell concentration level $\left(T_{\max }\right)$, the death rate of uninfected $\mathrm{CD}^{+}{ }^{+} \mathrm{T}$ cells $\left(d_{\mathrm{T}}\right)$ and the proportion of total memory $\mathrm{CD}^{+}{ }^{+} \mathrm{T}$ cells $\left(f_{\mathrm{m}}\right)$, but a smaller impact of $s$, the death rate of free viruses $\left(d_{\mathrm{V}}\right)$, the percentage of dividing memory $\mathrm{CD}^{+}{ }^{+}$cells $(m)$ and in vivo viral burst size $(N)$.

In specific, for patient 3 , which differed from patient 1 in parameters $s$ and $r$, the ranking of leading factors affected the likelihood changed over time. The rate of proliferation of $\mathrm{CD}^{+}{ }^{+} \mathrm{T}$ cells irritated by environmental antigens $(r)$ was most sensitive all through while the death rate of virus $\left(d_{\mathrm{V}}\right)$ and in vivo viral burst size $(N)$ kept remarkable influence as well. However, in the late-stage of disease, the effect of the proportion of total memory $\mathrm{CD} 4^{+} \mathrm{T}$ cells $\left(f_{\mathrm{m}}\right)$ surged and even exceeded that of $N$. The infectivity of R5 $\left(k_{\mathrm{R} 5}\right)$ showed an analogous trend.

Similarly, the enlargement of the value of $m$, which would result in the increase of $f_{\mathrm{m}}$ and the reduce of $f_{\mathrm{n}}$ (patient 6), would affect the results of sensitivity analysis to some extent. For instance, the sensitivity of $f_{\mathrm{m}}$ ascended due to the changing of $m$ (Figure 4). As for patient $7(r, N$, $f_{\mathrm{n}}$ increased; $s, m, f_{\mathrm{m}}, \mathrm{d}_{\mathrm{V}}$ decreased), the result is basically a nonlinear superposition of patient 3 (increased $r$; decreased $s$ ) and patient 6 (increased $m$ and $f_{\mathrm{m}}$; decreased $f_{\mathrm{n}}$ ).

\section{DISCUSSION}

The underlying causes for the R5-to-X4 shift in the late stage of HIV infection are not clearly understood. To find possible explanations, we developed a time-dependent mathematical model incorporating virus mutation to simulate the dynamics of HIV infection. The results are consistent with clinical observations, presenting an early viral peak, early decline of $\mathrm{CD} 4^{+} \mathrm{T}$ cells and subsequent short-term fluctuations both in virus load and $\mathrm{CD} 4^{+} \mathrm{T}$ cell count, followed by a progressive decline in $\mathrm{CD}^{+}{ }^{+} \mathrm{T}$ cells and a considerable rise in viral load. This model does not take dual tropic virus into consideration in order to reduce the dimensions. However, the model succeeded to explain that CXCR4-tropic virus appearing just in some individuals [2] may due to inter-individual variations. In this respect, it is important to point out that differences in the ability of viral infection among patients results in the differences in the evolution of X4 virus (Figure 2A, 2B). For example, just $10 \%$ lowering the infectivity of $\mathrm{X} 4$ virus, the amount of $\mathrm{X} 4$ virus decreased significantly, to almost $1 / 1000$ of the original counts (Figure 2B). By contrast, varying the initial load of R5 between 1 copy/ $\mathrm{mm}^{-3}$ and $10^{-3}$ copies $/ \mathrm{mm}^{-3}$ did not affect the occurrence of R5-to-X4 switch. Additionally, how parameters varying during the infection could also result in different results. Some reports suggest that the evolution of viral populations depends on the 'environment' within the host, which influences the immune control [19-21].

To understand the interplay between patients' characteristics and disease progression, we analyzed the effect of each factor to the disease progression. Illustrated by the case of patient 1 , the death rate of virus $\left(d_{\mathrm{T}}\right)$, in vivo viral burst size $(N)$, rate that uninfected $\mathrm{CD} 4^{+} \mathrm{T}$ cells arise from precursors $(s)$ and proliferate as stimulated by antigens $(r)$ appeared to be sensitive all the time. This phenomenon indicates that the renewal of $\mathrm{T}$ cells and virus played a more important role in the progression of disease than the infectivity of virus. Remarkably, compared with the death rate of uninfected T cells $\left(d_{\mathrm{T}}\right)$, the birth rate of new $\mathrm{CD} 4^{+}$ $\mathrm{T}$ cells was more significant. Furthermore, with the depletion of T cells, the influence of $s$ and $r$ increased and decreased respectively. While both representing the production of T cells, the difference between $s$ and $r$ is where the new $\mathrm{T}$ cells came from. The rising negative effect of $s$ is consistent with the observation that $\mathrm{X} 4$ viruses may cause more significant decrease than R5 viruses in the production of new $\mathrm{CD}^{+}{ }^{+} \mathrm{T}$ cells from the thymus [22].

Another notable phenomenon is that the infectivity of R5 strains $\left(k_{\mathrm{R} 5}\right)$, from a negative one, turned into a positive factor in the late stage while the infectivity of X4 virus $\left(k_{\mathrm{X} 4}\right)$ did not show the same influence. This result indicates that the hypothesis that R5-to-X4 switch happened because $\mathrm{X} 4$ variants may be more virulent than R5 variants might not be valid [3]. One possible explanation is that the target cells for X4 virus are naïve T cells. As a result, only raising the infectivity of $\mathrm{X} 4$ virus without increasing the amount of naïve $T$ cells will not promote the phenotypic switch.

As mentioned by Perelson et al. [3], the percentage of dividing memory T cells $(m)$ did have a significant effect on the likelihood to switch. However, their results only mentioned that the division rate regulates $\mathrm{R} 5$ and $\mathrm{X} 4$ viral load, but did not analyze how the alternation of $m$ would 
affect the evolution of switch. From our analysis, the increase of $m$ would make the infection of R5 on a vantage point and would have a negative impact on the R5-to-X4 switch. In contrast, the percentage of total memory cells $\left(f_{\mathrm{m}}\right)$ was a positive parameter. This may result from the experimental observation that a higher percentage of memory cells means a lower amount of dividing memory cells [3]. Additionally, the percentage of dividing memory $\mathrm{T}$ cells $(\mathrm{m})$ experienced a downward trend, while the percentage of total memory cells $\left(f_{\mathrm{m}}\right)$ experienced an upward trend. That is to say, despite the amount of new $\mathrm{CD} 4^{+} \mathrm{T}$ cells from normal environment raised, a lower production rate of T cells from thymus will still weaken the influence of $m$. The distinction might give the prompt that thymus may have a stronger relationship with the division of memory $\mathrm{T}$ cells than antigens do.

Moreover, the effect of the maximum $\mathrm{CD}^{+} \mathrm{T}$ cell concentration level $\left(T_{\max }\right)$ declined over time and so did that of the death rate of $\mathrm{CD} 4^{+} \mathrm{T}$ cell $\left(d_{\mathrm{T}}\right)$. This may shed some insight on the debate whether the emergence of HIV-1 strains able to use CXCR4 as a coreceptor is the cause or the consequence of immune decline, which we think both may be the cause [23].

The sensitivity analysis was also used to address the possible effects of different basic conditions. The results of this analysis were relatively robust. The structure of the model, which was determined by the molecular mechanisms, had a great influence on the outcome, even if parameters were disturbed significantly (Figure 4). As reflected in sensitivity analysis, parameters that would affect the results significantly were mostly $\mathrm{T}$ cells relevant $(r, m, s)$ which can mirror patients' physical states. To be specific, this study suggests typical indexes that are of substantial significance to viral tropism, pathogenesis, and antiretroviral therapy are these three factors: the percentage of dividing memory cell $(\mathrm{m})$, rate that uninfected $\mathrm{CD} 4^{+} \mathrm{T}$ cells arise from precursors $(s)$ and proliferate as stimulated by antigens $(r)$.

We should point out that changing the birth rate of new T cells would change the sequence of factors sorted by the influence in a decreasing manner. From the clinical perspective, it not only leads to the concern about personalized therapy on different patients, but also reminds us that, during the progression of disease, we should keep the therapeutic targets update in order to achieve optimal results. In specific the modification of a declined $s$ and an ascended $r$ favored the fitness of T cells, resulting in an increased influence for most parameters related to $\mathrm{T}$ cells and a decreased influence for those characterizing viruses. In conclusion, to study the phenomenon of HIV-1 tropism switch, we have presented a model that describes the dynamics of HIV-1 and $\mathrm{CD}^{+} \mathrm{T}$ cells, as well as their interactions. A systematic sensitivity analysis was applied to evaluate the influences of each possible factor on the viral phenotypic switch. Seven virtual patients with various physical states were examined horizontally and longitudinally. The results indicated that the death rate of virus $\left(d_{\mathrm{V}}\right)$, in vivo viral burst size $(N)$, rate that uninfected $\mathrm{CD} 4^{+}$T cells arise from precursors $(s)$ and proliferate as stimulated by antigens $(r)$ had significant influences on the likelihood to switch for most patients, though the specific sensitivity would fluctuate as disease progression. The decisive factors of tropism switch remained steady across heterogeneous patients, unless there were remarkable variations in the parameters concerning $\mathrm{CD} 4{ }^{+} \mathrm{T}$ cell renewal. It provides a new clinical thinking that therapy may focus on different factors according to different physical conditions and combined antiretroviral therapy might have much better effect.

\section{METHODS}

\section{Basic mathematical model for the dynamics of HIV}

It is widely appreciated that there are many uncertainty and random events in biological systems. However, the dynamics we concerned about are global behavior of numerous cells and viruses. As a result, we implied wellmixed population dynamics model, which has been proved applicative in this kind of problem [24]. The CCR5 receptor tropism is observed almost all primary HIV-1 isolates regardless of viral genetic subtype in early HIV-1 infection. To model the influence of R5 HIV-1 on $\mathrm{CD}^{+} \mathrm{T}$ cell growth in the early stages of infection, a simple mathematical model of the well-mixed population dynamics was defined based on the basic model first introduced by Perelson and colleagues in 1993 [25]. Let $T$ denotes the concentration of uninfected $\mathrm{CD}^{+}{ }^{+} \mathrm{T}$ cells in plasma, and $V_{\mathrm{R} 5}$ be the concentration of free infectious R5 virions. Upon infection, the $\mathrm{T}$ cells will become infected $\mathrm{CD} 4^{+}$T cells $I_{\mathrm{R} 5}$. Definitions and values of the parameters used in this paper are given in Supplementary Table S1. The dynamics of the interactions are represented by

$$
\begin{gathered}
\frac{d T}{d t}=s+r T\left(1-\frac{T+I_{\mathrm{R} 5}}{T_{\max }}\right)-\left(d_{\mathrm{T}}+k_{\mathrm{R} 5} V_{\mathrm{R} 5} f_{\mathrm{m}}\right) T, \\
\frac{d I_{\mathrm{R} 5}}{d t}=k_{\mathrm{R} 5} T V_{\mathrm{R} 5} f_{\mathrm{m}}-\left(d_{\mathrm{I}_{\mathrm{R}}}+c_{\mathrm{R} 5} T\right) I_{\mathrm{R} 5}, \\
\frac{d V_{\mathrm{R} 5}}{d t}=5 N \frac{m}{f_{\mathrm{m}}} d_{\mathrm{I}_{\mathrm{R} 5}} I_{\mathrm{R} 5}+N\left(1-\frac{m}{f_{\mathrm{m}}}\right) d_{\mathrm{I}_{\mathrm{R} 5}} I_{\mathrm{R} 5} \\
-\left(d_{V}+k_{\mathrm{R} 5} f_{\mathrm{m}} T+b_{\mathrm{R} 5} T\right) V_{\mathrm{R} 5} .
\end{gathered}
$$

In Equation (1a), naïve $\mathrm{CD} 4^{+} \mathrm{T}$ cells arise at a constant rate $s$ from precursors in the thymus. Once the signal 
activation is complete the $\mathrm{CD} 4^{+} \mathrm{T}$ cells then allows itself to proliferate. On account of the nutrition dependent competition mechanism, we assume the proliferation of activated T cells is governed by a logistic term, in which $r=r_{\max } p$ is the product of the maximum proliferation rate and the proportion of cells activated, and $T_{\max }$ is the saturating concentration factor. The initial stage of growth is approximately exponential; then, as saturation begins, the growth slows and the population level $T_{\max }$ is approached slowly from below. Since T cells have a natural lifespan, $d_{\mathrm{T}}$ is the average per capita death rate, which implies that the probability of cell death at time $t$ is given by an exponential distribution with an average cell lifetime of $1 / d_{\mathrm{T}}$ [26]. R5 HIV-1 infects uninfected memory T cells $\left(f_{\mathrm{m}} T\right)$ with a rate constant $k_{\mathrm{R} 5}$ and causes them to become productively infected cells $I_{\mathrm{R} 5}$, thus the mass-action type of term $k_{\mathrm{R} 5} T V_{\mathrm{R} 5} f_{\mathrm{m}}$ is subtracted from Equation (1a) and added to Equation (1b). Since the proportion of cells becoming latently infected upon infection is small [27], here we do not distinguish between latently infected and productively infected cells.

In Equation (1c), virus is produced by productively infected cells. We follow the assumption that dividing cells produce five times more virions during its lifetime than resting cells do [28]. As noted by Zhang et al. [28], dividing cells have approximately five times more virus RNA than resting cells do, we define $m$ to represent dividing memory $\mathrm{CD} 4^{+} \mathrm{T}$ cells. Thus, $m / f_{\mathrm{m}}$ denotes the proportion of dividing memory cells in total memory $\mathrm{CD} 4{ }^{+} \mathrm{T}$ cells. Since the average lifespan of a productively infected cell is $1 / d_{\mathrm{IR} 5}$, the average rate of virion production is $N d_{\text {IR5 }}$ [26] for resting cells and $5 N d_{\text {IR } 5}$ for dividing cells. Merrill suggests that $N$ is between 50 and 1000 [29]. Here we assume $N=200$. Note that free virus is cleared not only at rate $d_{\mathrm{V}} V_{\mathrm{R} 5}$ due to limited lifespan, but also at rate $k_{\mathrm{R} 5} T f_{\mathrm{m}} V_{\mathrm{R} 5}$ to account for the fact that whenever a $\mathrm{CD} 4^{+} \mathrm{T}$ cell is infected, at least one virion must enter.

In Equations (1b) and (1c), we take the immune response into consideration. The activation of immune response is usually $\mathrm{CD} 4^{+} \mathrm{T}$ cell-dependent. For example, the production of interleukin- 2 by $\mathrm{CD}^{+}{ }^{+} \mathrm{T}$ cells is necessary for the proliferation of activated cytotoxic $\mathrm{T}$ lymphocytes (CTL). Without $\mathrm{CD}^{+}{ }^{+} \mathrm{T}$ cell interactions, CTL do not proliferate and eventually become anergic. B cells are also activated by $\mathrm{CD}^{+}{ }^{+} \mathrm{T}$ cells through a phenomenon known as an immunological synapse [30,31]. By reasonably assuming the immune responses of CTL, macrophages, natural killer cells and $B$ cells to be proportional to the concentration of $\mathrm{CD}^{+} \mathrm{T}$ cells, we show that infected cells are killed by cellular immunity at rate $-c_{\mathrm{R} 5} T I_{\mathrm{R} 5}$, while free viruses are cleared by $\mathrm{B}$ celldependent humoral immunity at rate $-b_{\mathrm{R} 5} T V_{\mathrm{R} 5}$. Here the CTLs, macrophages, natural killer cells and B cells are only implicitly included in the model in order to reduce the dimensionality without losing crucial mechanism (see Supplementary Materials for detail).

\section{Sophisticated model for the dynamics of HIV}

The model given by Equations (1a), (1b) and (1c) describes the dynamics of HIV-1 disease while only CCR5-using virus exists. However, in late-stage infections, X4 strains become prevalent in about 50\% of patients [2]. To track the dynamics of two species, we extended the previous model and incorporated mutation rate.

$$
\begin{aligned}
& \frac{d T}{d t}=s+r T\left(1-\frac{T+I_{\mathrm{R} 5}+I_{\mathrm{X} 4}}{T_{\max }}\right) \\
& -\left(d_{\mathrm{T}}+f_{\mathrm{m}} k_{\mathrm{R} 5} V_{\mathrm{R} 5}+f_{n} k_{\mathrm{X} 4} V_{\mathrm{X} 4}\right) T, \\
& \frac{d I_{\mathrm{R} 5}}{d t}=f_{\mathrm{m}} k_{\mathrm{R} 5} T V_{\mathrm{R} 5}-\left(d_{\mathrm{I}_{\mathrm{R} 5}}+c_{\mathrm{R} 5} T\right) I_{\mathrm{R} 5} \text {, } \\
& \frac{d I_{\mathrm{X} 4}}{d t}=k_{\mathrm{X} 4} f_{\mathrm{n}} T V_{\mathrm{X} 4}-\left(d_{\mathrm{I}_{\mathrm{X}}}+c_{\mathrm{X} 4} T\right) I_{\mathrm{X} 4} . \\
& \frac{d V_{\mathrm{R} 5}}{d t}=5 N \frac{m}{f_{\mathrm{m}}} d_{\mathrm{I}_{\mathrm{R}}} I_{\mathrm{R} 5}+N\left(1-\frac{m}{f_{\mathrm{m}}}\right) d_{\mathrm{I}_{\mathrm{R} 5}} I_{\mathrm{R} 5} \\
& -a\left(5 N \frac{m}{f_{\mathrm{m}}} d_{\mathrm{I}_{\mathrm{R}}} I_{\mathrm{R} 5}+N\left(1-\frac{m}{f_{\mathrm{m}}}\right) d_{\mathrm{I}_{\mathrm{R} 5}} I_{\mathrm{R} 5}\right) \\
& +b\left(5 N \frac{n}{f_{\mathrm{n}}} d_{\mathrm{I}_{\mathrm{X} 4}} I_{\mathrm{X} 4}+N\left(1-\frac{n}{f_{\mathrm{n}}}\right) d_{\left.\mathrm{I}_{\mathrm{X} 4} I_{\mathrm{X} 4}\right)}\right. \\
& -\left(d_{\mathrm{V}}+f_{\mathrm{m}} k_{\mathrm{R} 5} T+b_{\mathrm{R} 5} T\right) V_{\mathrm{R} 5} .
\end{aligned}
$$

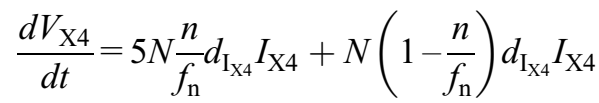

$$
\begin{aligned}
& +a\left(5 N \frac{m}{f_{\mathrm{m}}} d_{\mathrm{I}_{\mathrm{R}}} I_{\mathrm{R} 5}+N\left(1-\frac{m}{f_{\mathrm{m}}}\right) d_{\mathrm{I}_{\mathrm{R} 5}} I_{\mathrm{R} 5}\right)
\end{aligned}
$$

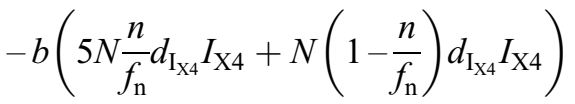

$$
\begin{aligned}
& -\left(d_{\mathrm{V}}+f_{\mathrm{n}} k_{\mathrm{X} 4} T+b_{\mathrm{X} 4} T\right) V_{\mathrm{X} 4} .
\end{aligned}
$$

In Equations (2a), (2b), (2c), (2d) and (2e), we took additional $\mathrm{X} 4$ viruses into consideration. Since the dynamics of CXCR4-tropic infection is analogous to CCR5-tropic infection [32], X4 virus infects uninfected $\mathrm{CD}^{+} \mathrm{T}$ cells with a rate constant $k_{\mathrm{X} 4}$ and become productively infected cells $I_{\mathrm{X} 4}$. Considering their different 
affinity to bind to naïve and memory $\mathrm{CD} 4^{+} \mathrm{T}$ cells, $f_{\mathrm{n}}$ replaces $f_{\mathrm{m}}$ and $f_{n} k_{X 4} T V_{X 4}$ is subtracted from Equation (2a) and added to (2c). Corresponding to $m$ representing the proportion of dividing memory T cells, $n$ demonstrates the percentage of dividing naïve T cells. When an infected naïve $\mathrm{T}$ cell disrupts, it releases

$$
5 N \frac{n}{f_{n}} d_{\mathrm{I}_{\mathrm{X}} 4} I_{\mathrm{X} 4}+N\left(1-\frac{n}{f_{n}}\right) d_{\mathrm{I}_{\mathrm{X} 4}} I_{\mathrm{X} 4}
$$

amount of viruses. Specifically, we assume that an R5 virus mutates to $\mathrm{X} 4$ virus at a rate $a$, and an $\mathrm{X} 4$ virus backward mutates to R5 virus at a rate $b$.

It is widely appreciated that the physical condition of patients changes over time as disease progressing. Here, to account for the gradual evolution from acute to chronic infection, we assume that virus infectivity increased with time and patients' immunity decreased with $\mathrm{CD}^{+}{ }^{+} \mathrm{T}$ cell counts. The rest of parameters varied according to the experimental data [11,33-35] (see Supplementary Materials for detail). Infection of memory cells by $\mathrm{X} 4$ viruses and infection of naïve cells by $\mathrm{R} 5$ viruses are not included in this model [3].

\section{Sensitivity analysis}

To systematically evaluate the influence of each factor on phenotype switch and the progression of disease, we conduct a sensitivity test, and the sensitivity factor of $x_{i}$ is calculated as [36]

$$
\left.S_{i} \equiv \frac{\partial F(\mathbf{x})}{\partial x_{i}}\right|_{\mathbf{x}=\mathbf{x}_{0}},
$$

where $F(\mathbf{x})$ is the objective function (e.g., the difference value of R5 and X4 virus load, total virus load), and $\mathbf{x}_{\mathbf{0}}$ is the local parameter profile. For simplicity, we use the finite difference Equation (4) to approximate the differential Equation (3).

$$
S_{\mathrm{V}, \mathrm{a}}=\frac{\frac{\left(V_{\mathrm{X} 4+}-V_{\mathrm{R} 5+}\right)-\left(V_{\mathrm{X} 4-}-V_{\mathrm{R} 5-}\right)}{V_{\mathrm{R} 5}+V_{\mathrm{X} 4}}}{\frac{\Delta a}{a}} .
$$

The sign of $S_{\mathrm{i}}$ represents the positive or negative correlation while the amplitude (absolute value) of $S_{\mathrm{i}}$ reflects the sensitivity strength (see Supplementary Materials for details). In our test, we set 7 patients with different parameter profiles (specially, the profile of patient 7 is the combination of patient 3,5 and 6) and did the parameter perturbation at different time points to figure out the sensitivity factor. The variations of most initial parameters are less than $20 \%$ and all the values are ensured within biological significance.

\section{SUPPLEMENTARY MATERIALS}

The supplementary materials can be found online with this article at DOI 10.1007/s40484-017-0107-4.

\section{AUTHOR'S CONTRIBUTIONS}

YW conceived and designed the study. WY and YW performed the study and analyzed the data. WY and YW wrote the manuscript. All of the authors read and approved the final manuscript.

\section{ACKNOWLEDGEMENTS}

We acknowledge the supports from the National Natural Science Foundation of China (Nos. 11402227, 11621062 and 11432012), the Fundamental Research Funds for the Central Universities of China (No. 2015QNA4034), and the Thousand Young Talents Program of China.

\section{COMPLIANCE WITH ETHICS GUIDELINES}

The authors Wei $\mathrm{Yu}$ and $\mathrm{Yu}$ Wu declare that they have no conflict of interests.

This article does not contain any studies with human or animal subjects performed by any of the authors.

\section{REFERENCES}

1. Pastore, C., Ramos, A. and Mosier, D. E. (2004) Intrinsic obstacles to human immunodeficiency virus type 1 coreceptor switching. J. Virol., 78, 7565-7574

2. Koot, M., Keet, I. P. M., Vos, A. H. V., de Goede, R. E. Y., Roos, M. T. L., Coutinho, R. A., Miedema, F., Schellekens, P. T. A. and Tersmette, M. (1993) Prognostic value of HIV-1 syncytiuminducing phenotype for rate of $\mathrm{CD}^{+}$cell depletion and progression to AIDS. Ann. Intern. Med., 118, 681-688

3. Ribeiro, R. M., Hazenberg, M. D., Perelson, A. S. and Davenport, M. P. (2006) Naïve and memory cell turnover as drivers of CCR5to-CXCR4 tropism switch in human immunodeficiency virus type 1: implications for therapy. J. Virol., 80, 802-809

4. Swanstrom, R. and Coffin, J. (2012) HIV-1 pathogenesis: the virus. Cold Spring Harb. Perspect. Med., 2, a007443

5. Sede, M. M., Moretti, F. A., Laufer, N. L., Jones, L. R. and Quarleri, J. F. (2014) HIV-1 tropism dynamics and phylogenetic analysis from longitudinal ultra-deep sequencing data of CCR5and CXCR4-using variants. PLoS One, 9, e102857

6. Sguanci, L., Bagnoli, F. and Liò, P. (2007) Modeling HIV quasispecies evolutionary dynamics. BMC Evol. Biol., 7, S5

7. Moore, J. P., Kitchen, S. G., Pugach, P. and Zack, J. A. (2004) The CCR5 and CXCR4 coreceptors - central to understanding the transmission and pathogenesis of human immunodeficiency virus type 1 infection. AIDS Res. Hum. Retroviruses, 20, 111-126

8. van Rij, R. P., Hazenberg, M. D., van Benthem, B. H. B., Otto, S. A., Prins, M., Miedema, F. and Schuitemaker, H. (2003) Early viral load and $\mathrm{CD}^{+} \mathrm{T}$ cell count, but not percentage of $\mathrm{CCR}^{+}$or $\mathrm{CXCR}^{+}{ }^{+} \mathrm{CD} 4{ }^{+} \mathrm{T}$ cells, are associated with R5-to-X4 HIV type 1 virus evolution. AIDS Res. Hum. Retroviruses, 19, 389-398 
9. Boyd, M. T., Simpson, G. R., Cann, A. J., Johnson, M. A. and Weiss, R. A. (1993) A single amino acid substitution in the V1 loop of human immunodeficiency virus type 1 gp120 alters cellular tropism. J. Virol., 67, 3649-3652

10. Cocchi, F., DeVico, A. L., Garzino-Demo, A., Cara, A., Gallo, R. C. and Lusso, P. (1996) The V3 domain of the HIV-1 gp120 envelope glycoprotein is critical for chemokine-mediated blockade of infection. Nat. Med., 2, 1244-1247

11. Fouchier, R. A. M., Groenink, M., Kootstra, N. A., Tersmette, M., Huisman, H. G., Miedema, F. and Schuitemaker, H. (1992) Phenotype-associated sequence variation in the third variable domain of the human immunodeficiency virus type 1 gp120 molecule. J. Virol., 66, 3183-3187

12. De Jong, J. J., De Ronde, A., Keulen, W., Tersmette, M. and Goudsmit, J. (1992) Minimal requirements for the human immunodeficiency virus type $1 \mathrm{~V} 3$ domain to support the syncytium-inducing phenotype: analysis by single amino acid substitution. J. Virol., 66, 6777-6780

13. McKnight, A. and Clapham, P. R. (1995) Immune escape and tropism of HIV. Trends Microbiol., 3, 356-361

14. Eckstein, D. A., Penn, M. L., Korin, Y. D., Scripture-Adams, D. D., Zack, J. A., Kreisberg, J. F., Roederer, M., Sherman, M. P., Chin, P. S. and Goldsmith, M. A. (2001) HIV-1 actively replicates in naive $\mathrm{CD}^{+}{ }^{+} \mathrm{T}$ cells residing within human lymphoid tissues. Immunity, 15, 671-682

15. Trouplin, V., Salvatori, F., Cappello, F., Obry, V., Brelot, A., Heveker, N., Alizon, M., Scarlatti, G., Clavel, F. and Mammano, F. (2001) Determination of coreceptor usage of human immunodeficiency virus type 1 from patient plasma samples by using a recombinant phenotypic assay. J. Virol., 75, 251-259

16. Connor, R. I., Sheridan, K. E., Ceradini, D., Choe, S. and Landau, N. R. (1997) Change in coreceptor use correlates with disease progression in HIV-1-infected individuals. J. Exp. Med., $185,621-628$

17. van 't Wout, A. B., Blaak, H., Ran, L. J., Brouwer, M., Kuiken, C. and Schuitemaker, H. (1998) Evolution of syncytium-inducing and non-syncytium-inducing biological virus clones in relation to replication kinetics during the course of human immunodeficiency virus type 1 infection. J. Virol., 72, 5099-5107

18. Verhofstede, C., Nijhuis, M. and Vandekerckhove, L. (2012) Correlation of coreceptor usage and disease progression. Curr. Opin. HIV AIDS, 7, 432-439

19. Regoes, R. R. and Bonhoeffer, S. (2005) The HIV coreceptor switch: a population dynamical perspective. Trends Microbiol., 13, 269-277

20. Tersmette, M. and Miedema, F. (1990) Interactions between HIV and the host immune system in the pathogenesis of AIDS. AIDS, 4 , S57-S66

21. Miedema, F., Tersmette, M. and van Lier, R. A. W. (1990) AIDS pathogenesis: a dynamic interaction between HIV and the immune system. Immunol. Today, 11, 293-297

22. Berkowitz, R. D., Alexander, S., Bare, C., Linquist-Stepps, V., Bogan, M., Moreno, M. E., Gibson, L., Wieder, E. D., Kosek, J.,
Stoddart, C. A., et al. (1998) CCR5- and CXCR4-utilizing strains of human immunodeficiency virus type 1 exhibit differential tropism and pathogenesis in vivo. J. Virol., 72, 10108-10117

23. Le, A. Q., Taylor, J., Dong, W., McCloskey, R., Woods, C., Danroth, R., Hayashi, K., Milloy, M. J., Poon, A. F. Y. and Brumme, Z. L. (2015) Differential evolution of a CXCR4-using HIV-1 strain in CCR5wt/wt and CCR $5 \Delta 32 / \Delta 32$ hosts revealed by longitudinal deep sequencing and phylogenetic reconstruction. Sci. Rep., 5, 17607

24. Regoes, R. and Bonhoeffer, S. (2002) HIV coreceptor usage and drug treatment. J. Theor. Biol., 217, 443-457

25. Perelson, A. S., Kirschner, D. E. and De Boer, R. (1993) Dynamics of HIV infection of $\mathrm{CD}^{+}{ }^{+} \mathrm{T}$ cells. Math. Biosci., 114, 81-125

26. Perelson, A. S. and Nelson, P. W. (1999) Mathematical analysis of HIV-1 dynamics in vivo. SIAM Rev., 41, 3-44

27. Phillips, A. N. (1996) Reduction of HIV concentration during acute infection: independence from a specific immune response. Science, 271, 497-499

28. Zhang, Z., Schuler, T., Zupancic, M., Wietgrefe, S., Staskus, K. A., Reimann, K. A., Reinhart, T. A., Rogan, M., Cavert, W., Miller, C. J., et al. (1999) Sexual transmission and propagation of SIV and HIV in resting and activated $\mathrm{CD} 4^{+} \mathrm{T}$ cells. Science, 286, $1353-1357$

29. Merrill, S. J. (1987) AIDS: Background and the dynamics of the decline of immunocompetence, pp. 59-75. In Theoretical Immunology Workshop

30. Kupfer, B., Kaiser, R., Rockstroh, J. K., Matz, B. and Schneweis, K. E. (1998) Role of HIV-1 phenotype in viral pathogenesis and its relation to viral load and $\mathrm{CD} 4{ }^{+}$T-cell count. J. Med. Virol., 56, 259-263

31. Dustin, M. L. and Shaw, A. S. (1999) Costimulation: building an immunological synapse. Science, 283, 649-650

32. Wilson, D. P., Mattapallil, J. J., Lay, M. D. H., Zhang, L., Roederer, M. and Davenport, M. P. (2007) Estimating the infectivity of CCR5-tropic simian immunodeficiency virus SIV (mac251) in the gut. J. Virol., 81, 8025-8029

33. Hellerstein, M. K., Hoh, R. A., Hanley, M. B., Cesar, D., Lee, D., Neese, R. A. and McCune, J. M. (2003) Subpopulations of long-lived and short-lived $\mathrm{T}$ cells in advanced HIV-1 infection. J. Clin. Invest., 112, 956-966

34. Hazenberg, M. D., Stuart, J. W., Otto, S. A., Borleffs, J. C. C., Boucher, C. A. B., de Boer, R. J., Miedema, F. and Hamann, D. (2000) T-cell division in human immunodeficiency virus (HIV)-1 infection is mainly due to immune activation: a longitudinal analysis in patients before and during highly active antiretroviral therapy (HAART). Blood, 95, 249-255

35. McCune, J. M., Hanley, M. B., Cesar, D., Halvorsen, R., Hoh, R., Schmidt, D., Wieder, E., Deeks, S., Siler, S., Neese, R., et al. (2000) Factors influencing T-cell turnover in HIV-1-seropositive patients. J. Clin. Invest., 105, R1-R8

36. Wu, Y., Lu, Y., Chen, W., Fu, J. and Fan, R. (2012) In silico experimentation of glioma microenvironment development and anti-tumor therapy. PLoS Comput. Biol., 8, e1002355 